\title{
Shock waves effects on localized adiposity caused by injectable GH: case study
}

\begin{abstract}
Summary
One of the most common local side effects of subcutaneous injection of human growth hormone $(\mathrm{GH})$ replacement therapy is lipodystrophy caused by adipocyte changes in specific areas. Shock waves have been shown to cause biological effects on cells and tissues, stimulating lipolysis. This study aims to investigate the efficacy of shock waves in reducing localized adiposity caused by injectable GH in its area of application.

An 18-year-old female patient with a complaint of abdominal adiposity caused by repeated GH in the region presented to clinic between April and July 2017. The patient was submitted to shock wave treatment under the following parameters: intensity of $3 \mathrm{bars}, 16 \mathrm{~Hz}$, and 4000pulses for 12 sessions. Ultrasonography, photogrammetry and perimetry images were used before treatment to measure baseline, then 15 and 30 days after treatment. The results showed an average decrease of $1.5 \mathrm{~cm}$ in abdominal circumference with a decrease in adipose layer thickness. This was also apparent through clinical images. It was concluded that both the patient's anthropometric data and ultrasonography images analyses showed consequent fat layer reduction and the integrity maintenance of the treatment adjacent areas.
\end{abstract}

Keywords: physiotherapy, growth hormone (gh), adiposity, lipolysis
Volume 2 Issue 4 - 2018

\author{
Patrícia Froes Meyer, Rodrigo Marcel \\ Valentim da Silva, Fabrícia Carliane Dantas \\ de Castro, Letícia de Medeiros Paiva \\ Fernandes, Tatiane Alice Ferreira de Lima, \\ Crislaine Cristina Bezerra de Araújo, Eneida \\ de Moraes Carreiro
}

Centro Universitario do Rio Grande do Norte (UNI-RN), Brasil

Correspondence: Patricia Froes Meyer, Centro Universitario do Rio Grande do Norte (UNI-RN), 59054-I80 Natal, RN, Brasil, Email Patricia.froesmeyer@gmail.com

Received: March 21, 2018 | Published: July 19, 2018

\section{Introduction}

The importance of hormones, including growth hormone, in the control of body metabolism is well documented. ${ }^{1,2}$ Experimental evidence demonstrates that $\mathrm{GH}$ helps in the mobilization of free fatty acids from adipose tissue for energy generation, increasing fat oxidation capacity as well as energy expenditure. ${ }^{3}$ Growth hormone replacement therapy is presented as a subcutaneously injectable solution. ${ }^{4,5}$

The treatment adverse effects are usually mild and transient Depending on the administered GH dose, fluid retention, muscle pain and joint stiffness are most commonly seen. ${ }^{6}$ Less frequently, localized reactions such as lipodystrophy may occur. This may present as lipohypertrophy (LH) or lipoatrophy (LA). ${ }^{7,8}$ These changes, otherwise, result from the redistribution of body fat, under the influence of GH, and loss (lipoatrophy) or accumulation (lipohypertrophy) of adipose tissue can occur in different areas. ${ }^{9}$

Treatment of patients with GH results in a relative loss of body fat and displaces the number of adipose cells and the volume of adipose cells to normal, indicating an adipogenic effect of $\mathrm{GH}$, however, their use on the skin can also cause accumulation of fat on the arms, legs or face when used in injectable form. Therefore, GH stimulates lipolysis, but it seems to regulate the deposition of lipids in adipose tissue. ${ }^{10}$

Lipodystrophy may be treated conservatively or surgically through liposuction. ${ }^{11}$ In case of conservative treatments, physiotherapy may help in lipolysis. Among the currently used treatments, shock waves therapy that aids in lipolysis is commonly used. Shock waves consist of mechanical acoustic waves produced and administered through a pneumatic applicator. They may lead to many biological effects on different types of cells and tissues. Since it is mechanical in nature, its actions result in unstable cavitation, which causes the adipose cell membrane rupture..$^{12-15} \mathrm{In}$ view of the presence of lipodystrophy after the application of $\mathrm{GH}$, this study aims to investigate the possible effects of shock waves as a lipodystrophy treatment modality.

\section{Material and methods}

An 18-year-old female, whose main complaint was the permanence of localized abdominal adiposity caused by $\mathrm{GH}$ application in this area presented to our clinic in Brazil in the city of Natal/RN between April and July 2017. The patient reported having started treatment with growth hormone at the age of nine, in 2007, for stunted growth. Subcutaneous hormone therapy was prescribed with upper limb and lower abdomen receiving the greatest number of subcutaneous injections. The treatment was interrupted due to the changes in the injected area with the appearance of a greater amount of fat observed in the right abdomen. This was further corroborated with ultrasonography revealing an accumulation of adipose cells in the area. The patient was instructed to perform warm compresses on the area with no benefit. In 2009, she underwent 10 physiotherapy sessions with high power ultrasound applications to decrease the fat, but did not obtain results. Shock wave treatment was presented as another possible treatment modality.

There were no appointed contraindications, such as pregnancy, pacemaker or the use of anti-coagulants, to receiving the treatment. Among the exclusion criteria are the lack of agreement with the Free and Informed Consent Term, as well as withdrawal during data collection.

The D-ACTOR ${ }^{\mathrm{TM}} 200$ shock wave device (STORZ MEDICAL AG, Switzerland) with the D20 tip was used. To evaluate the results, a high-frequency ultrasonography device MOBISSOM (12MHZ), a NIKON ${ }^{\mathrm{TM}}$ D5000 camera, a Fiber ${ }^{\mathrm{TM}}$ tape measure and a Glicomed ${ }^{\mathrm{TM}}$ balance was applied.

\section{Procedures}

The project was approved by the Ethics and Research Committee of the Potiguar University and the volunteer patient signed the Informed Consent Term (ICT) prior to treatment. The present study was based on the evaluation of the PAFAL protocol, validated by Meyer et al (2008), which includes the anthropometric data. 
Subsequently, the patient underwent ultrasound examination performed by an ultrasonographer. The exam was performed in the infra-abdominal region, in an area of $10 \mathrm{~cm}^{2}$ that was delimited with a pen, just below the umbilical scar, with the participant in the upright position, with the device set in S. Linear Multi-Frequency mode, 5 to $13 \mathrm{MHZ}, 5.0 \mathrm{~cm}$ of penetration, coupling the transducer longitudinally and transversely without pressure and providing inflammation data, fat layer thickness in $\mathrm{cm}$, density and fibrosis. The ultrasonography was performed in 3steps: before the application, 15days and 30days after the procedure and bilaterally, aiming to analyze the difference between the sides. Photos were recorded in an upright position, frontal, and lateral view (right and left) and the patient was asked to perform a $90^{\circ}$ shoulder flexion. The camera was fixed on a tripod at a height of $76 \mathrm{~cm}$ from the ground and placed at a distance of $44 \mathrm{~cm}$ from the volunteer. The circumference perimetry was measured using a tape measure positioned $5 \mathrm{~cm}$ below the umbilical scar and parallel to the floor.

To perform the treatment, the area was initially delimited in the infraumbilical region, $5 \mathrm{~cm}$ below the umbilicus downwards. The left side area was delimited with the same size for control. The participant was submitted to shock wave application performed in dorsal decubitus position in the same area the ultrasonography was performed. The set parameters were: intensity f 3 to $4 \mathrm{bars}, 16 \mathrm{~Hz}$ and 4000 pulses with treatment time being

10 minutes. The treatment consisted of 2 weekly sessions, totaling 12 sessions, and the reassessment was done at the end in relation to PAFAL before the application, 15days, and 30days after the procedure. The treated area was named A and the control area was named B as shown in Figure 1.

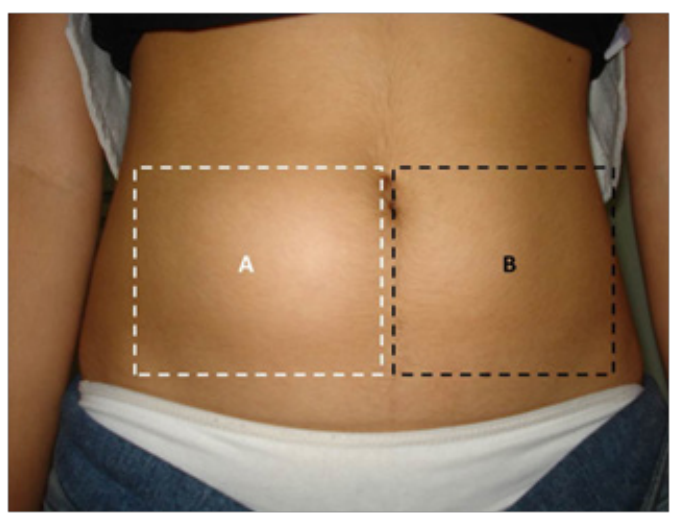

Figure I (A) Right side-treated area and (B) left side-control area.

\section{Results}

During the shock wave application period, the patient did not make any changes to her diet. The weight and perimetry variables evaluated before treatment and up to 30 days later are described in Table 1. There was an average decrease of $1.5 \mathrm{~cm}$ in her waist circumference. With regard to overall weight, $51 \mathrm{~kg}$ pre-treatment and $50 \mathrm{~kg}$ post-treatment were registered, with a small decrease of $1 \mathrm{~kg}$ of body weight by end of treatment.

Table I Patient anthropometric data

\begin{tabular}{llll}
\hline $\begin{array}{l}\text { Evaluation of } \\
\text { measurements and } \\
\text { weight }\end{array}$ & $\begin{array}{l}\text { Before } \\
\mathbf{( c m )}\end{array}$ & $\begin{array}{l}\text { I5days after } \\
\mathbf{( c m})\end{array}$ & $\begin{array}{l}\text { 30days } \\
\text { after }(\mathbf{c m})\end{array}$ \\
\hline $\begin{array}{l}\text { Abdominal circumference } \\
5 \mathrm{~cm} \text { below the umbilical } \\
\text { scar }\end{array}$ & $75 \mathrm{~cm}$ & $74 \mathrm{~cm}$ & $73,5 \mathrm{~cm}$ \\
\begin{tabular}{l} 
Weight $(\mathrm{kg})$ \\
\hline
\end{tabular} & $5 \mathrm{lkg}$ & $50 \mathrm{~kg}$ & $50 \mathrm{~kg}$ \\
\hline
\end{tabular}

\section{Ultrasonography results}

Ultrasonography data were recorded in Table 2 and obtained before Figures $2 \mathrm{~A} \& 2 \mathrm{~B}$, during and after the shock waves sessions (before, 15 and 30 days later). The adipose layer average thickness was obtained through simple arithmetic mean.

Table 2 Ultrasonography data with measures of thickness of the adipose layer referring to the treated side and the control side

\begin{tabular}{lllll}
\hline Measures & Before & I5days after & $\begin{array}{l}\text { 30days } \\
\text { after }\end{array}$ & $\begin{array}{l}\text { Abdominal } \\
\text { region }\end{array}$ \\
\hline $\begin{array}{l}\text { Thickness of the } \\
\text { adipose layer } \\
\text { (mean) }\end{array}$ & $1.24 \mathrm{~cm}$ & $1.19 \mathrm{~cm}$ & $0.89 \mathrm{~cm}$ & (Right) \\
\hline
\end{tabular}
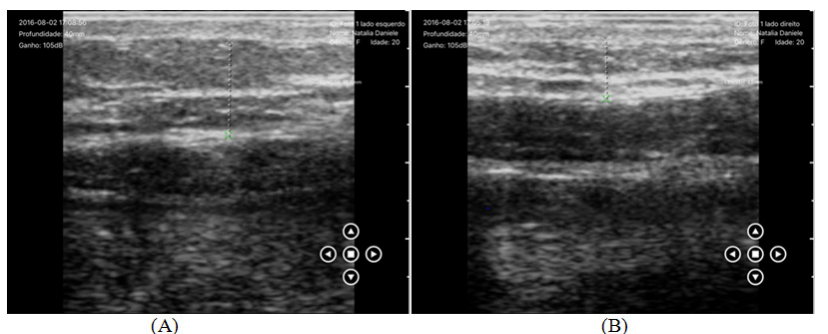

Figure 2 Ultrasonography images before the applications of shock waves, $(A)$ Right side-treated area and (B) left side-control area.

The ultrasonography results revealed a reduction in the thickness of the adipose layer at the end of the treatment, with a mean of $0.35 \mathrm{~cm}$ on the right periumbilical side and $0.15 \mathrm{~cm}$ on the control side. Fifteen days after the first session, there was a decrease of $0.05 \mathrm{~cm}$ in the adipose layer thickness on the treated side and of 0.13 on the control side, as shown in Figures 3A \& 3B. A significant reduction in local tissue adiposity was observed 30 days after treatment in the right infraumbilical region (Figures 4A \& 4B). At this stage, the decrease in the thickness of the adipose layer had an average of $0.30 \mathrm{~cm}$.

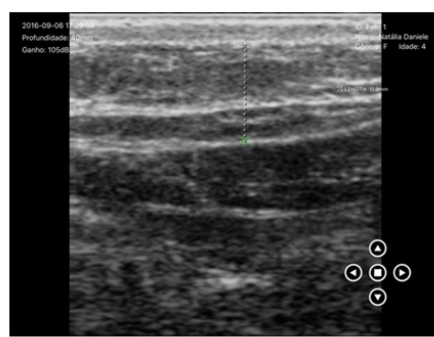

(A)

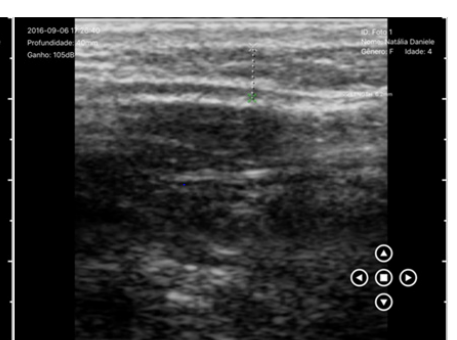

(B)
Figure 3 Ultrasonography images I5days after shock wave applications, (A) Right side-treated area and (B) left side-control area.

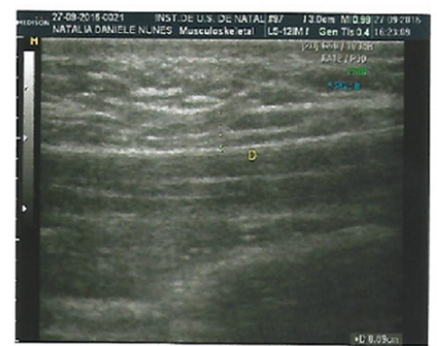

(A)

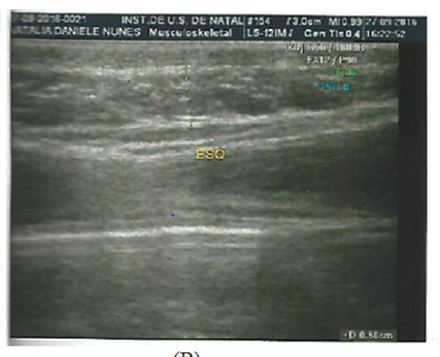

(B)
Figure 4 Ultrasonography images 30 days after the first session of shock wave applications, (A) Right side-treated area and (B) left side-control area.

The first ultrasound scan of the patient's abdominal wall revealed a solid hyperechogenic, oval, heterogeneous structure and coarse images, suggestive of a lipoma with diameters measuring $0.9 \times 1.3$ 
$\mathrm{x} 1.5 \mathrm{~cm}$ adjacent to the right rectus abdominis muscle Figures $2 \mathrm{~A}$ $\& 2 B$. In the last ultrasonography Figures $4 A \& 4 B$ the presence of six structures was evidenced, suggestive of adipose cluster to the umbilical region, to the right on the abdominal wall, which largest diameters corresponding to $0.6 \times 1.0 \times 1.1 \mathrm{~cm}$.

\section{Photo analysis}

The analysis of the photos was recorded in frontal and lateral views, obtained before Figures 5A \& 5B, during Figures $6 \mathrm{~A} \& 6 \mathrm{~B}$ and after the shock wave application Figures 7A \&7B. There was a decrease in mean abdominal circumference, comparing pre-treatment and post-treatment photos, showing difference in the patient's abdominal adiposity in a perceptible way, better observed from the lateral perspective.

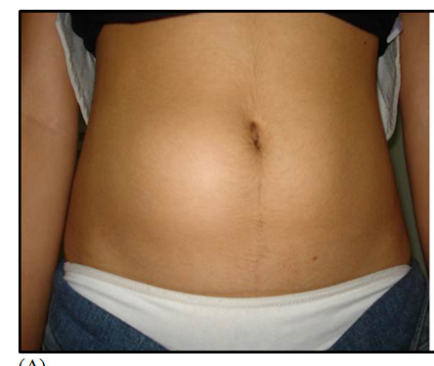

(A)

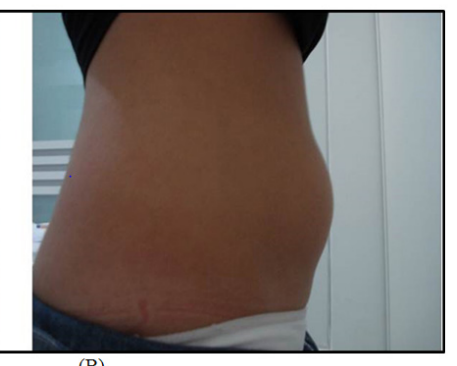

(B)
Figure 5 Photographic images before shock wave applications, (A) frontal and (B) lateral perspectives.

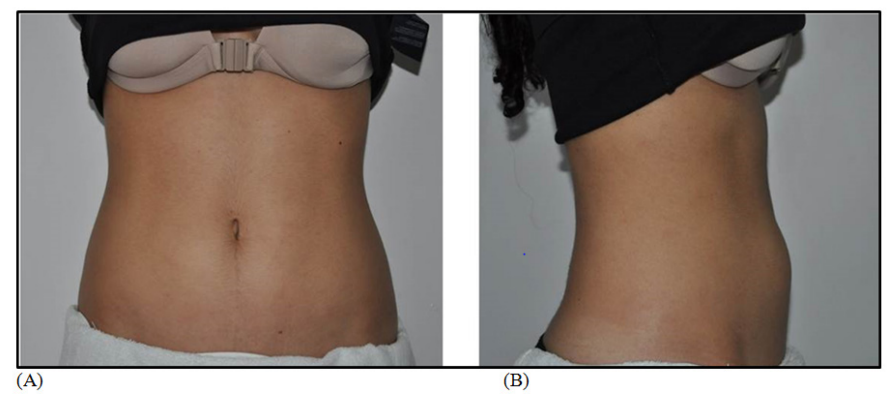

Figure 6 Photographic images I5days after the start of shock wave applications, (A) frontal and (B) lateral perspectives.

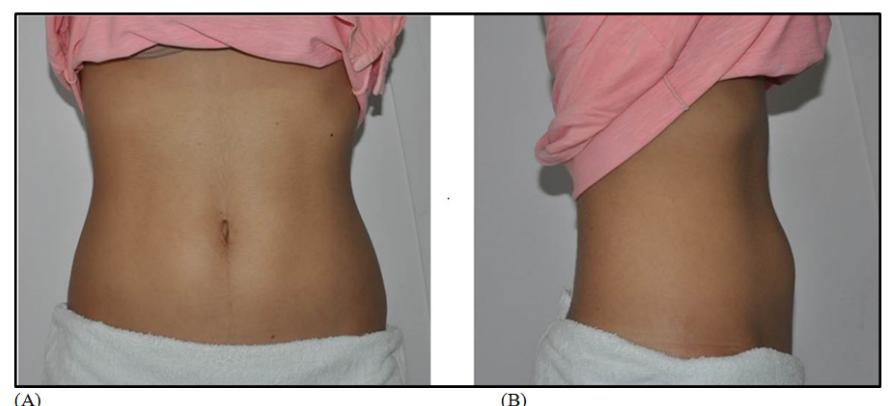

Figure 7 Photographic images 30days after the first of 12 sessions of shock wave application, (A) frontal and (B) lateral perspectives.

\section{Discussion}

Lipodystrophy is a common localized reaction to $\mathrm{GH}$ hormone replacement therapy. While surgical treatment is an option, conservative methods are more attractive to most patients. Shock wave therapy is a method that uses shock waves to break down adipocyte cell membrane and cause lipolysis in the area treated. This treatment does not change a person's weight as described by Ferraro et al. ${ }^{13}$ This suggests that the reduction of fat thickness was due to the treatment of shock waves and cryolipolysis.

The presence of asymmetric changes in subcutaneous adipose tissues, suggestive of lipomatous agglomerate in the right paraumbilical area was observed in the study of the patient's abdominal wall ultrasonography. ${ }^{13,16}$ Only one medical report, among several, described the adipose tissue alteration found in the patient as a lipoma. Zanini ${ }^{16}$ described the lipoma as a more common mesenchymal neoplasm, being a benign tumor of mature adipocytes of variable size, single or multiple, preferentially located in the limbs and trunk, clinically manifested as a nodule or subcutaneous tumor, more palpable than visible. Conventional surgical treatment is suggested in literature as more effective, especially in the presence of muscular or tissue infiltration. ${ }^{17}$ Conservative treatments are not cited as successful therapeutic possibilities in these cases. ${ }^{18}$

In other reports, this was defined as an adipose cluster. Heid et al., ${ }^{19}$ defined the difference between lipoma, lipomatosis and lipodystrophy. Lipomas being consistent with fat cells that constitute hypodermic nodular formations. They can be simple or multiple (lipomatosis). Lipodystrophies are a heterogeneous group or family of acquired conditions, and sometimes associated to metabolic diseases. In this case, two ultrasound medical reports pointed to the description of lipodystrophy induced by GH replacement therapy. Due to the absence of conservative treatment response of a lipoma, as described in the literature, this further proves that the cause is an acquired lipodystrophy that responded well to shock wave therapy. ${ }^{20}$

Gomes et al. ${ }^{21}$ carried out a case study with a 43 -year-old female volunteer with abdominal lipodystrophy who did not undergo any type of diet, but practiced some physical activity (light walking) once a week and was submitted to ten sessions of high power ultrasound. During the treatment, the patient did not make any changes to her diet, did not use medication and did physical exercise only on the day of the session, maintaining the usual frequency and intensity. The results revealed significant reduction in measurements and body weight, so it was then concluded that high-power ultrasound presented satisfactory results in localized lipodystrophy. The photographic images recorded before and after the treatment demonstrated significant fat reduction in the treated areas, similar to this study's findings. The patient, in that case, did not present a drug-induced lipodystrophy as in this case. It is important to emphasize that their patient underwent highpower ultrasound treatment in the same physiotherapy service in 2009 and did not obtain results cited by these authors, probably due to a different lipodystrophy cause.

Liang et al., ${ }^{22}$ compared shock wave therapy to ultrasound. The number of waves required for lipolysis was lower in the shock wave treatment, resulting in a shorter treatment time compared to the time for treatment with the ultrasound. In the present study, perimetry and ultrasonography results demonstrated significant reduction of local tissue adiposity in the first 15days after treatment, as shown in Figures $6 \mathrm{~A} \& 6 \mathrm{~B}$

Studies with humans and animals have verified the effectiveness of shock waves in adipose tissue. ${ }^{22,23}$ The pilot study of shock wave lipolysis performed by Liang et al.,22 used two different species of animals, a rabbit and a pig of approximately 3.5 and $2.5 \mathrm{~kg}$ respectively. On microscopic tissue test samples examination, the fat cell region with its membranes were destroyed after shock wave treatment. This was clearly observed and no damage to neighboring tissues such as skin, blood vessels and peripheral nerves were observed. ${ }^{22,23}$

Liang et al. ${ }^{24}$ when testing tissue withdrawn from an euthanized animal and also withdrawn from living fat tissues obtained results that 
evidenced that the largest lesion occurred to living fat tissue rather than fat tissue removed from the euthanized animal. No new fat cells generation was found within one week after the shock wave treatment. What happens to fat cells destroyed through shock wave treatment in clinical application is that they are transported through a series of routes to the liver or other tissues, being absorbed in phagocytosis processes. ${ }^{22,24}$ The observation of sliced fat tissues suggests that fat cells were possibly destroyed by two mechanisms - compression and cavitation. It was assumed that the area of injury might have actually increased due to the post-treatment dissolution of the affected fat cells. ${ }^{24}$

In the study conducted by Adatto et al., ${ }^{25}$ the treatment was performed with shock waves in 14 female patients during 4weeks, with eight treatment sessions using two applicators. Measurements with the ultrasound system clearly demonstrated significant decrease in the subcutaneous fat layer thickness and reduction in the mean circumference of the thighs, as well as decrease in the waist circumference measurement. These studies demonstrated the noninvasive treatment safety and efficacy of localized fat areas, not only by providing volume reduction in but also by improving skin texture..$^{25}$

The study carried out by Adatto et al., ${ }^{25}$ used electromagnetic shock waves, whereas the present study was carried out with pneumatic shock waves. A relationship between this study and the other mentioned studies is observed due to the proven efficacy between conservative treatments in localized lipodystrophies. It is possible to conclude that these effects are due to the treatments. These parametric studies related to shock wave administration have been conducted in skin/fat tissues of humans and animals confirm lipolysis. Clinical studies are key and challenging tasks to verify the success and viability of shock waves in lipolysis.

These initial results are promising, but a more in-depth study is suggested for possible clinical application of this therapy. ${ }^{22-25}$ In this research, great difficulty in finding bibliographical references must be mentioned, especially in regard to intervention with scientific proof. The lack of sufficient studies demonstrates that shock waves have been used with little scientific basis in relation to their application in lipodystrophies. Additional studies with larger number of volunteers are recommended.

\section{Authors' contribution}

The authors declare that they have participated in the design, results analyses, and effectively contributed in carrying out this study and make public responsibility for its contents, in which affiliations or financial agreements between authors and companies that may be interested in publishing this study were not omitted.

\section{Acknowledgements}

None.

\section{Conflict of interest}

The authors state that they do not have any conflict of interests with the subject discussed in this article or to the mentioned products/ items. The authors declare that this study and article are unique and that this work, in part or in full, or any other work with substantially similar content has not been submitted to another journal.

\section{References}

1. Lange KH. Fat metabolism in exercise-with special reference to training and growth hormone administration. Scand J Med Sci Sports. 2004;14(2):74-99.

2. Doessing S, Kjaer M. Growth hormone and connective tissue in exercise Scand J Med Sci Sports. 2005;15(4):202-210.
3. Vinicius FC, José DJ, Julio T, et al. Hormônio do crescimento e exercício físico: considerações atuais. Rev Bra de Ciên Farmac. 2008;44(4):549-562.

4. Hoppen A, Perassolo MS. Tratamento com hormônio do crescimento: baixa estatura versus envelhecimento. Rev Conhecimento Online. 2010;1(2):1-17.

5. Silva AAL, De Bortoli CSH, Optiz SP, et al. Evaluation of the technique of subcutaneous administration of heparin in the formation of bruises. Rev Bra de Enferm. 2002;55(2);128-133.

6. Hoybye C, Christiansen JS. Growth hormone replacement in adultscurrent standards and new perspectives. Best Pract Res Clin Endocrinol Metab. 2014;29(1):115-123.

7. Souza FM, Collett-Solberg PF. Adverse effects of growth hormone replacement therapy in children. Arq Bras Endocrinol Metabol. 2011;55(8):559-565.

8. Gentile S. Strollo F, Ceriello A, et al. Lipodystrophy in Insulin-Treated Subjects and Other Injection-Site Skin Reactions: Are We Sure Everything is Clear? Diabetes Therapy. 2016;7(3):401-409.

9. Figueiredo F, Paulo P, Val AC, et al. Lipodistrofia generalizada congênita/Congenital generalized lipodystrophy. $J$ pediatr (Rio J). 2004;80(4):333-336.

10. Chaves VE, Júnior FM, Bertolini GL. The metabolic effects of growth hormone in adipose tissue. Endocrine. 2013;44(2):293-302.

11. Macedo ACB, Oliveira SM. A atuação da fisioterapia no pré e pósoperatório de cirurgia plástica corporal: Uma revisão de literatura. Cader da Esc de Saúde. 2014;1(4):169-189.

12. Silva JG, Eduardo F, Fatima FF. Physical therapy in the treatment of body aesthetics dysfunctions-literature review. Manual Therapy, Posturology \& Rehabilitation Journal. 2014;12:979-1012.

13. Ferraro GA. De Francesco F, Cataldo C, et al. Synergistic effects of cryolipolysis and shock waves for noninvasive body contouring. Aesthetic plastic surgery. 2012;36(3):666-679.

14. Angehrn, Kuhn C, Voss A. Can cellulite be treated with low-energy extracorporeal shock wave therapy? Clin Interv Aging. 2007;2(4):623-630.

15. Neuland GH, et al. Induktion adulter mesenchymaler Stammzellen durch estrakorporale Stosswellen zur Regeneracion muskulos kelettaler Gewebe. Orth Praxis. 2006;42(4):57-64.

16.Zanini M. Use of cortislesteroid intralesional no lipoma management. Ibero-Latin-American cutaneous medicine. 2006;34(5-6):309-311.

17. Aboudib JHC, Giaquinto MGC, Carvalho EJC. Lipoma Breast Giant-Case Report. Brasilian Journal of Plastic Surgery. 2002;17(2):123-130.

18. Gaucher S, Maladry D, Silitra AM, et al. Removal of subcutaneous lipomas: Interest of liposuction. J Cosmet Dermatol. 2017;16(3):400-401.

19. Heid E, Christian C. Lipomes cutanés, lipomatoses, lipodystrophies. Encycl Méd Chir. 2002.

20. Huczak L, Driban NE, et al. Lipoma and lipomatosis. Rev Argent Dermatol. 2007;88(1):56-66.

21. Gomes LCS, do Carmo KF. et al. Effects of high power ultrasound in the treatment of localized lipodystrophy: Case report. Revista Eletrônica de Saúde e Ciência. 2015;5(2):26-32.

22. Liang SM. Chun-Neng Y, Jing-Jou Y, et al. An in-vitro experiment on lysing adipose tissue by shock waves. Journal of Medical and Biological Engineering. 2008;28 (4):203-209.

23. Chang MH, Lin SY. Development of an Omnidirectional-Capable Electromagnetic Shock Wave Generator for Lipolysis. J Healthc Eng. $2017 ; 9258512$ 
24. Liang SM, Kuang-Fu Z, Jing-Jou Y, et al. Animal study on lysing adipose tissues by shock waves. Journal of medical and biological engineering. 2009;30(3):145-151.
25. Adatto MA, Adatto-Neilson R, Novak P, et al. Body shaping with acoustic wave therapy AWT®/EPAT $\AA$ : Randomized, controlled study on 14 subjects. J Cosmet Laser Ther. 2011;13(6):291-296. 